\title{
The epidemiology of sepsis in a Brazilian teaching hospital
}

Authors

Kauss IAM $^{1}$

Cintia MC Grion ${ }^{2}$

Cardoso LTQ ${ }^{2}$

Anami EHT ${ }^{3}$

Nunes LB ${ }^{4}$

Ferreira GL ${ }^{4}$

Matsuo $\mathrm{T}^{5}$

Bonametti $\mathrm{AM}^{2}$

${ }^{1}$ Physiotherapy

Department, Universidade Estadual de Londrina,

Paraná, Brazil.

${ }^{2}$ Clinical Medical

Department, Universidade

Estadual de Londrina,

Paraná, Brazil.

${ }^{3}$ Nurse Department,

Hospital Universitário de

Londrina, Paraná, Brazil.

${ }^{4}$ Medical Student,

Universidade Estadual de

Londrina, Paraná, Brazil.

${ }^{5}$ Statistics Department,

Universidade Estadual de

Londrina, Paraná, Brazil.

Submitted on: $8 / 21 / 2009$ Approved on: 12/14/2009

Correspondence to: Cintia M C Grion

Rua Vila Lobos, 580, Jardim Mediterrâneo

Londrina - PR - Brazil

CEP: 86047-130

Phone: +55-43-33428635

Phone (mobile): +55-4399945090

Fax: +55-43-33712466

E-mail: cintiagrion@

sercomtel.com.br

We declare no conflict of interest.

\begin{abstract}
Objectives: The objective of this study was to estimate disease incidence and mortality rate of sepsis in a tertiary public hospital. Methods: Patients admitted to the Intensive Care Unit (ICU) in 2004 and 2005 were monitored for sepsis using an observational longitudinal study design. Patients were monitored daily for diagnostic criteria of sepsis, according to ACCP/SCCM Consensus Conference criteria, until either death or hospital discharge. Results: During the study, we analyzed 1,179 patients. Systemic Inflammatory Response Syndrome (SIRS) was present in 1,048 (88.9\%) patients on admission, and was associated with infection in $554(47.0 \%)$ patients. Of these, sepsis was diagnosed in $30(2.5 \%)$ patients, while severe sepsis was diagnosed in $269(22.8 \%)$ patients, and septic shock was diagnosed in $255(21.6 \%)$ patients. APACHE II and SOFA scores were higher in septic patients ( $\mathrm{p}<0.001$ ), and the ensuing mortality rates were $32.8 \%$ (IC 95\%: $21.6-45.7 \%$ ) for patients with sepsis, 49.9\% (IC 95\%: 44.5-55.2\%) for severe sepsis, and 72.7\% (IC 95\%: 68.1-76.9\%) for septic shock. Conclusions: The data from our study revealed a high incidence of sepsis among hospitalized patients. Moreover, sepsis patients had a high rate of mortality.
\end{abstract}

Keywords: sepsis, incidence, mortality, epidemiology.

[Braz J Infect Dis 2010;14(3):264-270] CElsevier Editora Ltda.

\section{INTRODUCTION}

Sepsis is a syndrome that affects the public health system and represents a challenge to health care providers and managers. Epidemiological data revealed a high incidence of sepsis in patients hospitalized in Intensive Care Units (ICU) compared with the occurrence of disease in general population. ${ }^{1,2}$ Multicentre epidemiologic studies ${ }^{2-4}$ have applied sepsis definitions from the American College of Chest Physicians/ Society of Critical Care Medicine Consensus Conference $^{5}$ to electronic hospital database records based on standardized diagnoses by International Coding Diagnosis classification, and identified a possible underestimation of sepsis incidence among hospitalized patients. Martin et al. evaluated these previous studies and estimated both high positive and high negative predictive values $(97.7 \%$ and $80 \%$, respectively). The high negative predictive value resulted in $18.8 \%$ of sensibility; implying that four out of five cases of severe sepsis in hospitalized patients were missed. ${ }^{1,3}$

Further complicating the monitoring effort, studies that applied consensus defini- tions to identify the incidence of sepsis only considered patients admitted to the ICU ${ }^{5}$ and excluded sepsis patients admitted to other areas within the hospital. So, in fact, studies based on consensus definitions only reported the epidemiology of treated sepsis cases.

Worldwide, approximately $10 \%$ of patients admitted to the ICU presented with severe sepsis. ${ }^{1}$ In the United States, sepsis was responsible for $2.26 \%$ hospital admissions in 1995 , presenting an annual population incidence of 3.0 per 1000 habitants. ${ }^{2}$ Thereafter, an $8.7 \%$ increase in annual incidence of sepsis was observed from 1979 through 2000, and the hospitalization rate due to severe sepsis nearly doubled from 1993 to $2003 .^{3-4}$

Despite technological and therapeutic advances, mortality among sepsis patients remains high, varying from $30 \%$ to $60 \% .^{6}$ In 1995, an epidemiological study that included seven states in the United States identified a $28.6 \%$ mortality rate among sepsis patients, resulting in 215,000 deaths per year. ${ }^{2}$ More recently, an European study conducted in 198 ICU in 24 countries showed $32.2 \%$ mortality at 
60 days of follow-up of patients with severe sepsis and 54\% mortality in patients with septic shock. ${ }^{7}$

The incidence of sepsis and mortality in patients with sepsis in Latin American is largely unknown. ${ }^{8,9}$ One study of patients in five ICU from the south and southeast regions of Brazil reported an incidence density of 57.9 per 1000 patientsday (CI 95\%: 51.5-65.3), or 421 cases of sepsis resulting in 30.5 per 100 ICU admissions..$^{10}$ The authors described 241 cases of severe sepsis and 203 cases of septic shock, resulting in 17.4 (CI 95\%: 16.5-18.6) and 14.7 (CI 95\%: 13.9-15.5) per 100 ICU admissions, respectively. Mortality was higher in patients with severe sepsis (46.9\%) and septic shock (52.2\%), compared to sepsis (33.9\%). ${ }^{10}$ Additional studies showed that the incidence and mortality of sepsis in Brazilians admitted to the ICU are among the highest in the world. ${ }^{6,11}$ Understanding the reasons for the elevated incidence of sepsis in Brazil is the first step to improving prevention, diagnosis, and care of septic patients in this country.

The objective of this study was to estimate the incidence of sepsis and associated mortality among diagnosed patients in the ICU of Londrina University Hospital. The study was conducted for two years, and the results were compared with similar studies documented in the literature.

\section{METHODS}

We used a prospective longitudinal study design with consecutive sampling of patients admitted to the ICU in Londrina University Hospital (LUH). LUH is a teaching hospital with 330 beds, serving an estimated population of 825,000 inhabitants. The study took place from January 1, 2004, to December 31, 2005. Exclusion criteria were (1) less than 18 years of age, (2) less than 24 hours ICU length of stay, and (3) more than one ICU admission during the same hospital stay. During the first 24 hours following admission, we collected demographic data, diagnoses on ICU admission and chronic diseases, according to the Acute Physiology and Chronic Health Evaluation II (APACHE II) score definitions. We also collected laboratory and clinical data for calculation of the APACHE II score, as originally described. ${ }^{12}$

Diagnostic criteria for Systemic Inflammatory Response Syndrome (SIRS), sepsis, severe sepsis, and septic shock were evaluated daily. Some patients were classified into more than one diagnostic category during hospitalization because the diagnostic categories represent an evolution of sepsis. The stages of sepsis were diagnosed according to the American College of Chest Physicians/Society of Critical Care Medicine Consensus Conference. ${ }^{5}$ SIRS was defined as the presence of two or more of the following criteria: temperature above $38^{\circ} \mathrm{C}$ or below $36^{\circ} \mathrm{C}$; tachycardia (heart rate more than 90 beats/min); tachypnoea manifested by a raised respiratory rate (more than 20 breaths/min) or hyperventilation (partial pressure of $\mathrm{CO}_{2}$ in arterial blood $<32 \mathrm{mmHg}$ ) or mechanical ventilation; or altered white blood cell count (more than $12,000 / \mathrm{mm}^{3}$, less than $4000 / \mathrm{mm}^{3}$ or more than $10 \%$ of band forms). Sepsis was defined as the presence of infection associated with SIRS. If organ dysfunction resulted from sepsis, the case was defined as severe sepsis, and septic shock was defined when sepsis resulted in arterial hypotension needing vasopressors, despite initial volume resuscitation. The onset of sepsis was considered the moment when screening and confirmatory criteria were first documented on patients' records.

Organ dysfunction was evaluated daily, based on clinical and laboratory variables of the Sequential Organ Failure Assessment (SOFA), as previously described. ${ }^{13}$ Center for Disease Control and Prevention (CDC) criteria were applied to diagnose nosocomial infection. ${ }^{14}$ Infection site was defined by the attending physician and classified as: pulmonary, abdominal, urinary, blood, bone, skin/soft tissues, others, and undetermined. Diagnosis of community infection was done by the attending physician, based on clinical, laboratory, microbiologic variables, and image diagnostic methods.

Patients were stratified into septic and non-septic groups for 28 days survival analysis. The non-septic group included patients classified as non-SIRS, SIRS, and localized infection. The septic group included patients with sepsis, severe sepsis, or septic shock diagnosed anytime during their stay in ICU.

Patients presenting with more than one diagnosis of sepsis due to evolution of their septic state, were classified according to the most severe form at clinical presentation.

Data were collected until either death or ICU discharge, or at 28 days of ICU stay. Survival rates were established for patients discharged before 28 days by monitoring for subsequent hospitalizations, and by ambulatory consultations or phone calls.

Data collection was standardized and performed by the main investigator and trained subinvestigators. Sources of data were patient hospital records and the electronic hospital database. EpiInfo 3.3.2 version, Centers for Disease Control (CDC, Atlanta, GA), was used to store collected data. Data entry was standardized and errors or out of range values were checked.

The study was approved by the local Ethics Committee and informed patient consent was waived.

\section{STATISTICAL ANALYSIS}

Sample size calculation ${ }^{15}$ of 1,520 patients for longitudinal studies was performed using the Epitable program from EpiInfo, 6.04b version (CDC), considering the infinite size of the population: $45 \%$ expected frequency of septic patients, ${ }^{10}$ $2.5 \%$ error margin and $95 \%$ confidence interval.

Continuous variables with normal distribution were expressed as mean and standard deviation, and with nonnormal distribution as median and interquatiles. Categorical variables were expressed as proportions. Descriptive statistics were applied to describe all relevant variables. 
Bivariate analysis was applied to compare septic and nonseptic groups. Student's $t$ test or nonparametric equivalent (Mann-Whitney) tests for non normal distribution were used to compare continuous variables. Proportions of categorical variables were compared using Pearson chi-square test.

Survival probabilities were estimated for septic and nonseptic patients using the Kaplan-Meier method. The logrank test was applied to compare survival times of the two independent groups of patients.

A significance level of 5\% was adopted and statistical analyses were performed with EpiInfo 3.3.2 version, (CDC), and MedCalc for Windows 9.3.2.0 version (MedCalc Software, Mariakerke, Belgium).

\section{RESULTS}

During the study period, 1,694 patients were admitted to the ICU. Of these, 38 were excluded from analysis because they were younger than 18 years of age, 346 were excluded for staying in the ICU less than 24 hours, 109 were excluded for more than one admission to the ICU, and 22 were excluded because of insufficient data. A total of 1,179 patients were analyzed (Figure 1).

Patients admitted to the ICU were predominately male (57.1\%) and the median age was 59 (42-72) years. Most admissions were for clinical treatment $(70.1 \%)$, followed by elective surgeries (24.7\%), and emergency surgeries (5.2\%). Original hospital location assignments by department were the emergency department (48\%), followed by the operating room (29.9\%), and wards (22.1\%). The most frequent diagnoses on ICU admission were sepsis (40.3\%), neurological diseases $(5.2 \%)$, coronary artery disease $(4.7 \%)$, postoperative period of gastrointestinal surgery (4.0\%), and intracranial hemorrhage (3.8\%). Chronic disease diagnosis, according to APACHE II definitions, was present in 159 (13.5\%) patients, and immunosuppression was the most frequently diagnosed disease.

Median ICU length of stay was 4 (2-9) days, and hospital length of stay was 16 (9-32) days. Median APACHE II score for all patients was 21 (13-28). Non-survivor patients had a median APACHE II score that was significantly higher

Figure 1: Fluxogram of patients analyzed in the study and diagnoses ( $\mathrm{n}$ and \%) on admission according to International Consensus Conference definitions.

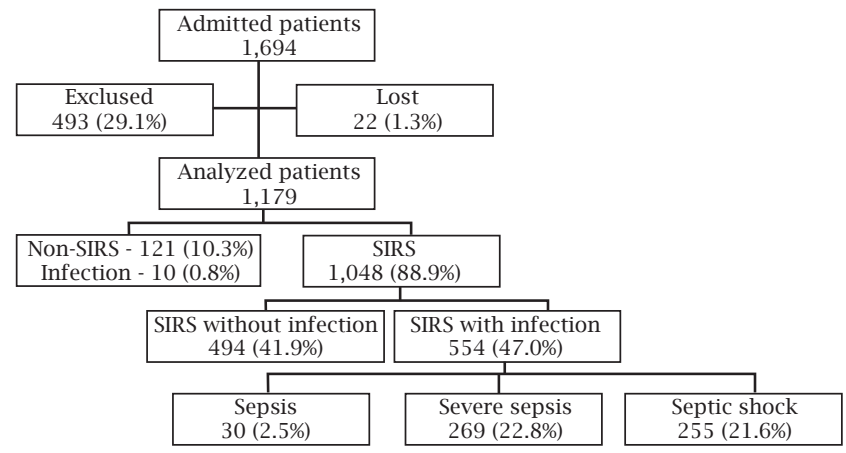

(27; IQ: 20-33) than survivors (16; IQ: 11-23) $(\mathrm{p}<0.001)$. The median SOFA score on ICU admission was 6 (3-9) and was significantly higher for non-survivors (median $=8$; IQ: 6-11), as compared to survivors (median $=4$; IQ: 2-7) $(\mathrm{p}<0.001)$. Mortality at 28 days of follow-up was $42.2 \%$ (CI 95\%: 39.3\%-45\%).

On ICU admission, 131 patients (11.1\%) did not present with SIRS criteria and $10(0.8 \%)$ of these patients had localized infection. SIRS criteria were present in 1,048 patients (88.9\%), among whom $554(47 \%)$ had an associated infection focus. Among these 554 patients, we recorded sepsis in 30 (2.5\%), severe sepsis in 269 (22.8\%), and septic shock in 255 (21.6\%) (Figure 1). The median APACHE II score was 13 (10-18) for patients without SIRS; 16 (11-23) for those with SIRS but without infection; 19 (10-27) for patients with localized infection; 22 (13-27) for sepsis; 23 (17-28) for severe sepsis; and 30 (26-36) for patients with septic shock. The median SOFA on ICU admission was 4 (2-6) for patients without SIRS; 4 (2-7) for SIRS without infection; 6 (3-7) for localized infection; 4.5 (2-8) for sepsis; 6.0 (4-8) for severe sepsis; and 10 (9-12) for patients with septic shock.

Patients were systematically evaluated using diagnostic criteria throughout the ICU stay. The evaluation revealed 28 (2.4\%) patients with localized infection, 64 (5.4\%) with sepsis, 353 (29.9\%) with severe sepsis, and 412 (34.9\%) with septic shock. Patients were classified in more than one diagnostic category if they presented with worsening of clinical condition. The most frequent infection site was pulmonary $(66.5 \%)$, followed by the urinary system (13.6\%), abdomen (6.6\%), skin/ soft tissues (4.4\%), and others (8.9\%). Infection was classified as community acquired in 291 (32.4\%) cases, nosocomial in 300 (33.4\%) cases, and ICU acquired in 308 (34.3\%) cases. Among 712 patients with infection, 168 (23.6\%) presented with more than one infection site. The mortality rates were $35.7 \%$ (CI 95\%: 18.6-55.9\%) for patients with infection, 32.8\% (CI 95\%: 21.645.7\%) for patients with sepsis, $49.9 \%$ (CI 95\%: 44.5-55.2\%) for patients with severe sepsis, and 72.7\% (IC 95\%: 68.1-76.9\%) for septic shock patients. Figure 2 describes patients according to the 28 day outcome and sepsis diagnoses classification (sepsis, severe sepsis, and septic shock).

Figure 2: Mortality rate (\%) according to sepsis diagnostic criteria.

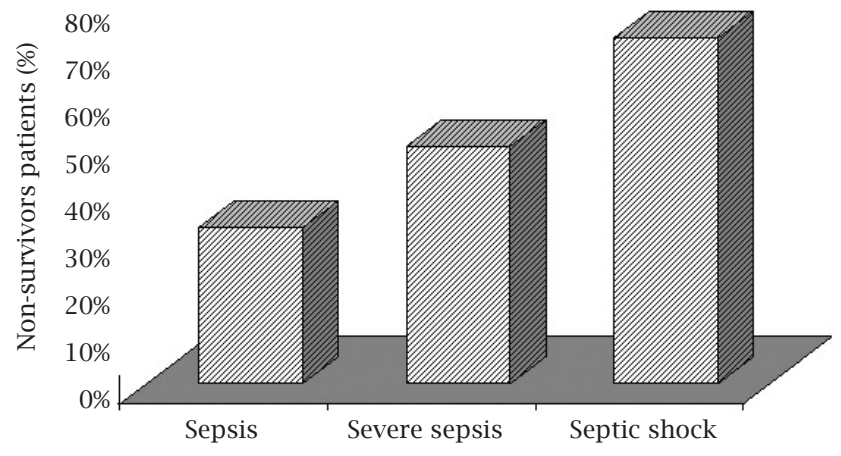


Patients were stratified into septic $(697 ; 59.1 \%)$ and nonseptic $(482 ; 40.9 \%)$ groups, based on only one diagnostic category for each patient. Among septic patients, 48 (6.9\%) were classified as sepsis, $353(50.6 \%)$ as severe sepsis, and 296 (42.5\%) as septic shock patients. Males were predominant among septic patients (60.0\%), compared to non-septic $(52.9 \%)(\mathrm{p}=0.015)$. Septic patients were also older $(62 ; 43$ 74 years) compared to non-septic patients (56; 41-68 years) ( $\mathrm{p}<0.001)$. Most septic patients were admitted for clinical therapeutic procedures $(83.4 \%$ ), while $51.0 \%$ of non-septic patients were clinical admissions (Table 1).

Surviving septic patients had a median ICU length of stay of 8 (4-18) days, while non-septic patients had a shorter stay in ICU (median $=2$ days; IQ: $2-3$ days) ( $\mathrm{p}$ $<0,001)$. Septic patients also remained in the hospital longer (median $=27$ days; IQ: 16-48 days) compared to non-septic patients (median $=15$ days; IQ: 9-27 days) $(\mathrm{p}<0.001)$ (Table 2). Chronic disease was more frequent among septic patients $(\mathrm{p}<0.001)$, and APACHE II scores were higher in septic patients compared to non-septic patients $(\mathrm{p}<0.001)$.

Organ dysfunction in both groups was evaluated by SOFA score. We applied SOFA on the first day of sepsis for septic patients and on the first day of ICU admission for non-septic patients. SOFA scores were higher for septic patients (median $=8$; IQ: 6-10) as compared to non-septic

Table 1. General characteristics of septic and non-septic patients

\begin{tabular}{|c|c|c|c|c|c|}
\hline \multirow{2}{*}{$\begin{array}{l}\text { Variables } \\
\text { Male (n and \%) }\end{array}$} & \multicolumn{2}{|c|}{$\begin{array}{l}\text { Non-septic } \\
(\mathrm{n}=482)\end{array}$} & \multicolumn{2}{|c|}{$\begin{array}{c}\text { Septic } \\
(\mathrm{n}=697)\end{array}$} & \multirow{2}{*}{$\begin{array}{c}\text { p-value } \\
0.015^{*}\end{array}$} \\
\hline & 255 & 52.9 & 418 & 60.0 & \\
\hline \multicolumn{6}{|l|}{ Age (years) } \\
\hline Mean and standard deviation & 54.6 & 18.0 & 58.1 & 19.6 & $<0.001^{\dagger}$ \\
\hline Median (Interquartile) & 56 & $41-68$ & 62 & $43-74$ & $<0.001^{\ddagger}$ \\
\hline \multicolumn{6}{|l|}{ Type of admission ( $\mathrm{n}$ and \%) } \\
\hline Medical & 246 & 51.0 & 581 & 83.4 & $<0.001^{*}$ \\
\hline Surgical & 236 & 49.0 & 116 & 16.6 & $<0.001$ \\
\hline Elective & 216 & 44.9 & 75 & 10.7 & $<0.001$ \\
\hline Urgency & 20 & 4.1 & 41 & 5.9 & $0.235^{*}$ \\
\hline Chronic disease (n and \%) & 43 & 8.9 & 116 & 16.6 & $<0.001^{*}$ \\
\hline \multicolumn{6}{|l|}{ Apache II score } \\
\hline Mean and standard deviation & 15.7 & 7.7 & 25.3 & 8.9 & $<0.001^{\dagger}$ \\
\hline Median (Interquartile) & 14 & $10-20$ & 26 & $19-31$ & $<0.001^{\ddagger}$ \\
\hline \multicolumn{6}{|l|}{ SOFA } \\
\hline Mean and standard deviation & 4.1 & 3.0 & 8.1 & 3.5 & $<0.001^{\dagger}$ \\
\hline Median (Interquartile) & 3 & $2-6$ & 8 & $6-10$ & $<0.001^{\ddagger}$ \\
\hline 28 days mortality (n and \%) & 101 & 21.0 & 396 & 56.8 & $<0.001^{\prime \prime}$ \\
\hline
\end{tabular}

"Chi square test

‘Student's $t$ test

" Mann-Whitney test

Table 2. ICU and hospital length of stay of survivor patients

\begin{tabular}{|cccccc}
\hline \multicolumn{1}{c}{ Variables } & \multicolumn{2}{c}{ Non-septic } & \multicolumn{2}{c}{ Septic } & p-value \\
\hline ICU length of stay (days) & & & & & \\
$\quad$ Mean and standard deviation & 2.9 & 2.2 & 14.3 & 17.6 & $<0.001^{+}$ \\
Median (Interquartile) & 2 & $2-3$ & 8 & $4-18$ & $<0.001^{\ddagger}$ \\
\hline Hospital length of stay (days) & & & & & $<0.001^{+}$ \\
Mean and standard deviation & 19.9 & 15.2 & 36.0 & 27.8 & $<0.001^{\ddagger}$ \\
\hline Median (Interquartile) & 15 & $9-27$ & 27 & $16-48$ & \\
\hline
\end{tabular}

† Student's t test

₹ Mann-Whitney test 
patients (median $=3$; IQ: $2-6)(\mathrm{p}<0.001)$. General characteristics of patients in both groups are shown on Table 1. APACHE II and SOFA scores were higher in non-survivors from both groups (data not shown). Kaplan-Meier analysis of patients after 28 days of follow-up revealed survival probabilities of $79.0 \%$ and $43.2 \%$ for non-septic and septic patients, respectively ( $\mathrm{p}<0.001$ ) (Figure 3 ).

Figure 3: Kaplan-Meier survival analysis of septic and nonseptic patients.

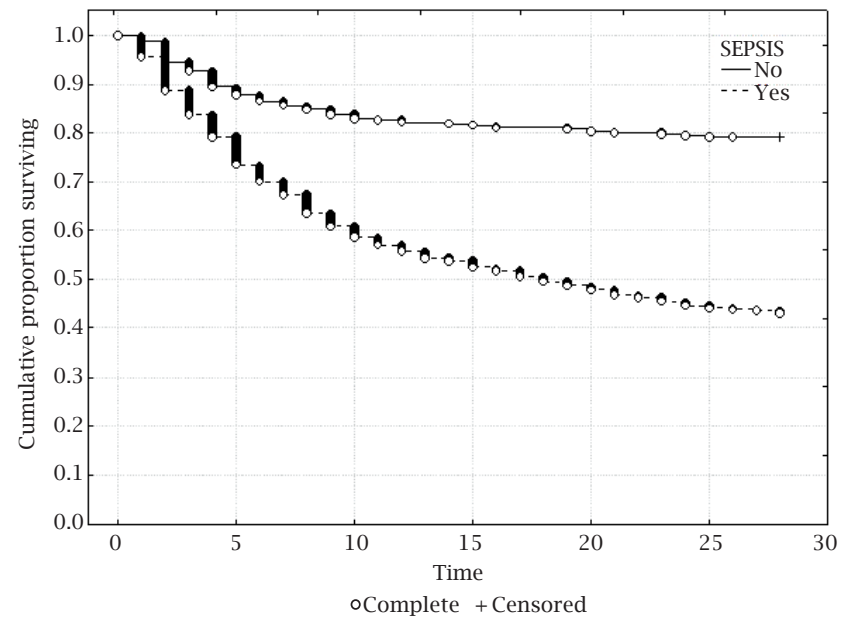

\section{DISCUSSION}

This study evaluated the incidence of sepsis in patients admitted to the ICU in a teaching hospital at Londrina, in the south of Brazil. This ICU has predominantly clinical admissions with a high proportion of patients with sepsis diagnosis on admission, presenting with high severity of disease and mortality.

Across studies, the reported proportion of septic patients admitted to the ICU may vary according to study design, study population, and type of ICU, as well as public health strategies adopted locally. In our study, we only evaluated patients hospitalized in the ICU, but even when compared with similar populations of patients reported in literature, we observed a higher incidence of severe sepsis and septic shock among our patients upon admission.

In other countries, the incidence of sepsis ranged between 7.9 and $11.4 \%$ on ICU admission. ${ }^{16-18}$ A multicentre study $^{18}$ evaluated sepsis epidemiologic data in France and reported a higher incidence of sepsis in teaching or regional hospitals (15.3\%), and general hospitals (14.9\%), compared to private hospitals $(8.5 \%)(\mathrm{p}<0.008)$. Disease incidence was also higher in ICU patients in hospitals with more than 400 beds $(15.4 \%)$ compared to small hospitals (11.6\%) $(\mathrm{p}=0.016)$. These results suggested high risk patients are preferentially admitted to larger hospitals. The incidence of sepsis was higher in medical ICU (17.2\%) or mixed surgicalmedical ICU (15\%) compared to surgical ICU (11.9\%) $(\mathrm{p}=0.005)$.

Other studies showed higher incidences of sepsis on ICU admission, which varied from $22.9 \%$ to $42 \% .^{7,19-23}$ Important multicentre studies that used epidemiological data from several countries reported high variability in sepsis incidence, even between ICUs located in the same country. Possible explanations include difference in health care policies, hospital characteristics, admission ICU criteria, and population characteristics. Albert and colleagues (2002) conducted a multicentre cohort study in 28 ICU from Europe, Canada, and Israel and observed variability in sepsis incidence that ranged from $1.5 \%$ in a Canadian ICU to $66.5 \%$ in a British ICU. ${ }^{20}$ A recent SOAP (Sepsis Occurrence in Acutely Ill Patients) study ${ }^{7}$ evaluated 198 ICU in 24 European countries and found similar variability with reports of $18 \%$ sepsis incidence in Switzerland and 73\% incidence in Portugal.

Results from our study compare favorably with data from Britain ${ }^{21,22}$ and other European countries. ${ }^{7}$ Similarities between data from different studies are most likely due to the lack of ICU beds across different health systems. In Brazil, limitations on human resources and materials create the lack of ICU facilities, but in other countries, such as the United Kingdom, the lack of ICUs is more likely related to the political emphasis placed on primary health care. This highlights the potential impact of health care politics on incidence of sepsis on admission to an ICU.

The BASES study (2004) identified 31.8\% (281/884) of patients admitted for more than 24 hours with sepsis on ICU admission, ${ }^{10}$ while we similarly detected sepsis in $47 \%$ (554/1179) of patients admitted to the ICU. Our incidence rate was higher than rates reported in other studies done in Brazil and other countries. Several factors may have contributed to our higher rate of incidence. Our hospital is a referee health service to a large region in southern Brazil, and our ICU is predominantly medical with a limited number of ICU beds. ${ }^{24}$ These characteristics are also associated with higher nosocomial infection rates, ${ }^{19,20,25}$ which could increase sepsis incidence during hospitalization. In support of this possibility, Karlsson and colleagues ${ }^{26}$ found a lower incidence of sepsis in patients in the ICU $(10.5 \%)$ in an institution in Finland that had a low frequency of multiresistant bacteria and is supported by a health system that allows early access to health care.

In addition to studying sepsis incidence at ICU admission, our study also evaluated the occurrence of sepsis during patients' stay in the ICU. We found a significant increase in the number of sepsis cases with time spent in the ICU. Out of 697 patients classified as septic, $554(79.5 \%)$ fulfilled diagnostic criteria on the first day in the ICU and 143 (20.5\%) developed diagnostic criteria in the subsequent days. 
Other Brazilian published data corroborated the increase in sepsis incidence we observed during ICU stay. The BASES study detected $281(67.7 \%)$ sepsis cases on admission and another 134 (32.3\%) cases during hospital stay, ${ }^{10}$ Recently, another study describing sepsis incidence in teaching hospitals in South Brazil reported the occurrence of 31.9\% sepsis cases, $24.5 \%$ severe sepsis cases and $31.4 \%$ septic shock cases during ICU stay. ${ }^{27}$

Methodological variations in epidemiologic studies make it difficult to compare results across studies. Even with the application of the same diagnostic criteria, there are variations in study design, and inclusion and exclusion criteria, which probably account for some of the differences seen. However, in general, our results described a higher incidence of sepsis in ICU patients than reported in other studies, including those from the Brazilian population.

Sepsis mortality is multifactorial and there are several risk factors identified in literature, including prognostic scores, ${ }^{7,18,25}$ associated chronic diseases, ${ }^{28}$ acute organ dysfunction, ${ }^{3,7,18,25}$ alcoholism, ${ }^{29}$ age, , $^{2,7,25,30}$ and infection characteristics. ${ }^{7,23,25,28,31}$ Additionally, sepsis management according to Surviving Sepsis Campaign can also change the disease prognosis and reduce patient mortality. ${ }^{32}$

Variability is high among epidemiological studies evaluating sepsis mortality. Here, we could not detect differences between mortality in patients with localized infection (35.7\%) and sepsis (32.8\%), possibly because less complicated clinical presentations of infection were observed in a population of critically ill patients, and patient deaths were not due to infection. Within a general population, infection and sepsis are usually associated with lower mortality rates. On the other hand, we detected progressively increased mortality in cases of severe sepsis (49.9\%) and septic shock (72.7\%). Our results correspond to those of Albert and colleagues (2003), who described similar hospital mortality for localized infection (25.5\%) and sepsis (25.5\%), as well as increased mortality in patients with severe sepsis $(40.9 \%)$ and septic shock $(60.5 \%) .^{28}$

When we compared the survival curve of septic patients and non-septic patients, we found a significant difference in prognosis between these two groups of patients. Sepsis reduced early survival, evaluated at 28 days of follow-up. Although septic patients usually are older, male, and have associated chronic diseases, sepsis has been described as an independent risk factor for death by other authors. ${ }^{7,25,28,33}$

\section{CONCLUSION}

In conclusion, we observed a high incidence of sepsis and an increased mortality among sepsis patients in our study. The rates of sepsis incidence and mortality were higher in our study than in previously published data from Brazil and other countries.

\section{REFERENCES}

1. Linde-Zwirble WT, Angus DC. Severe sepsis epidemiology: sampling, selection, and society [commentary]. Crit Care 2004; 8:222-6.

2. Angus DC, Linde-Zwirble WT, Lidicker J et al. Epidemiology of severe sepsis in the United States: Analysis of incidence, outcome, and associated costs of care. Crit Care Med 2001; 29:1303-10.

3. Martin GS, Mannino DM, Eaton S et al. The Epidemiology of Sepsis in the United States from 1979 through 2000. N Engl J Med 2003; 348:1546-54.

4. Dombrovskiy VY, Martin AA, Sunderram J, Paz HL. Rapid increase in hospitalization and mortality rates for severe sepsis in the United States: A trend analysis from 1993 to 2003. Crit Care Med 2007; 35:1244-50.

5. American College of Chest Physicians/Society of Critical Care Medicine Consensus Conference. Definitions for sepsis and organ failure and guidelines for the use of innovative therapies in sepsis. Crit Care Med 1992; 20:864-74.

6. Angus DC, Pereira CAP, Silva E. Epidemiology of severe sepsis around the world. Endocr Metab Immune Disord Drug Targets 2006; 6:7-16.

7. Vincent JL, Sakr Y, Sprung CL et al. Sepsis in European intensive care units: Results of the SOAP study. Crit Care Med 2006; 34:344-53.

8. León-Rosales SP, Molinar-Ramos F, Domínguez-Cherit G, Rangel-Frausto MS, Vázquez-Ramos VG. Prevalence of infections in intensive care units in Mexico: A multicenter study. Crit Care Med 2000; 28:1316-21.

9. Dougnac LA, Mercado FM, Cornejo RR et al. Prevalencia de sepsis grave en las unidades de cuidado intensivo. Primer estúdio nacional multicéntrico. Rev Med Chil 2007; 135:620-30.

10. Silva E, Pedro M de A, Sogayar AC et al. Brazilian Sepsis Epidemiological Study (BASES study). Crit Care 2004; 8:R251-60.

11. Moreno R, Afonso S, Fevereiro T. Incidence of sepsis in hospitalized patients. Current Infectious Disease Reports 2006; 8:346-50.

12. Knaus WA, Draper EA, Wagner DP, Zimmerman JE. APACHE II: A severity of disease classification system. Crit Care Med 1985; 13:818-28.

13. Vincent JL, de Mendonça A, Cantraine F et al. Use of the SOFA score to assess the incidence of organ dysfunction/failure in intensive care units: Results of a multicenter, prospective study. Crit Care Med 1998; 26:1793-800.

14. Garner JS, Jarvis WR, Emori TG, Horan TC, Hughes JM. CDC definitions for nosocomial infections, 1988. Am J Infect Control 1988; 16:128-40.

15. Fleiss J L. Statistical methods for rates and proportions. 2th edn. Hoboken: John Wiley \& Sons, 1981.

16. Záhorec R, Firment J, Straková J et al. Epidemiology of severe sepsis in intensive care units in the Slovak Republic. Infection 2005; 33:122-8.

17. Salvo I, de Cian W, Musicco M et al. The Italian SEPSIS study: preliminary results on the incidence and evolution of SIRS, sepsis, severe sepsis and septic shock. Intensive Care Med 1995; 21:S244-9.

18. Brun-Buisson C, Meshaka P, Pinton P, Vallet B. EPISEPSIS Study Group. EPISEPSIS: a reappraisal of the epidemiology and outcome of severe sepsis in French intensive care units. Intensive Care Med 2004; 30:580-8.

19. Engel C, Brunkhorst FM, Bone HG et al. Epidemiology of sepsis in Germany: results from a national prospective multicenter study. Intensive Care Med 2007; 33:606-18. 
20. Albert C, Brun-Buisson C, Burchardi H et al. Epidemiology of sepsis and infection in ICU patients from an international multicentre cohort study. Intensive Care Med 2002; 28:10821.

21. Padkin A, Goldfrad C, Brady AR et al. Epidemiology of severe sepsis occurring in the first 24 hrs in intensive care units in England, Wales, and Northern Ireland. Crit Care Med 2003; 31:2332-8.

22. Harrison DA, Catherine AW, Eddleston JM. The epidemiology of severe sepsis in England, Wales and Northern Ireland, 1996 to 2004: secondary analysis of a high quality clinical database, the ICNARC case mix programme database. Crit Care 2006; 10:R42.

23. Adrie C, Alberti C, Chaix-Couturier C et al. Epidemiology and economic evaluation of severe sepsis in France: age, severity, infection site, and place of acquisition (community, hospital, or intensive care unit) as determinants of workload and cost. J Crit Care 2005; 20:46-58.

24. Cardoso LTQ. Admissão tardia em unidade de terapia intensiva como fator de risco para mortalidade: um estudo de coorte prospectivo [thesis]. Londrina, PR, Brazil: Universidade Estadual de Londrina; 2008, 82 pp.

25. Vincent JL, Bihari DJ, Suter PM et al. The prevalence of nosocomial infection in intensive care units in Europe. Results of the European Prevalence of Infection in Intensive Care (EPIC) Study. JAMA 1995; 274:639-44.
26. Karlsson S, Varpula M, Ruokonen E et al. Incidence, treatment, and outcome of severe sepsis in ICU-treated adults in Finland: the Finnsepsis study. Intensive Care Med 2007; 33:435-43.

27. Zanon F, Caovilla JJ, Michel RS et al. Sepse na unidade de terapia intensiva: etiologias, fatores prognósticos e mortalidade. Revista Brasileira de Terapia Intensiva 2008; 20:128-34.

28. Albert C, Brun-Buisson C, Goodman SV et al. Influence of systemic inflammatory response syndrome and sepsis on outcome of critically Ill infected patients. Am J Respir Crit Care Med 2003; 168:77-84.

29. O Brien JM Jr, Lu B, Ali NA et al. Alcohol dependence is independently associated with sepsis, septic shock, and hospital mortality among adult intensive care unit patients. Crit Care Med 2007; 35:345-50.

30. Martin GS, Mannino DM, Moss M. The effect of age on the development and outcome of adult sepsis. Crit Care Med 2006; 34:15-21.

31. Damas $P$, Ledoux D, Nys $M$ et al. Intensive care unit acquired infection and organ failure. Intensive Care Med 2008; 34:856-64.

32. Dellinger RP, Levy MM, Carlet JM et al. International guidelines for management of severe sepsis and septic shock: 2008. Crit Care Med 2008; 36:296-327.

33. Annane D, Aegerter P, Jars-Guincestre MC et al. Current epidemiology of septic shock. The CUB-RÉA Network. Am J Respir Crit Care Med 2003; 168:165-72. 